\title{
Pyruvate Enolate Arylation and Alkylation: OBO Ester Protected Pyruvates as Useful Reagents in Organic Synthesis
}

\author{
C. Henrique Alves Esteves, ${ }^{a}$ Christopher J. J. Hall, ${ }^{a}$ Peter D. Smith ${ }^{\mathrm{b}}$ and Timothy J. Donohoe ${ }^{\mathrm{a} *}$ \\ ${ }^{a}$ Department of Chemistry, University of Oxford, Chemistry Research Laboratory, Mansfield Road, Oxford, OX1 3TA, UK \\ ${ }^{b}$ AstraZeneca, Pharmaceutical Sciences, Silk Road Business Park, Macclesfield, SK10 2NA, UK
}

\begin{abstract}
A protected pyruvate equivalent is described that allows arylation and arylation/alkylation reactions to be performed at the methyl group. Utilization of the OBO derivative of the pyruvate ester allowed the application of palladium catalyzed arylation reactions together with subsequent alkylation, under basic conditions. Moreover, the OBO protecting group could be easily removed in one step to provide access to a wide range of substituted pyruvate derivatives.
\end{abstract}
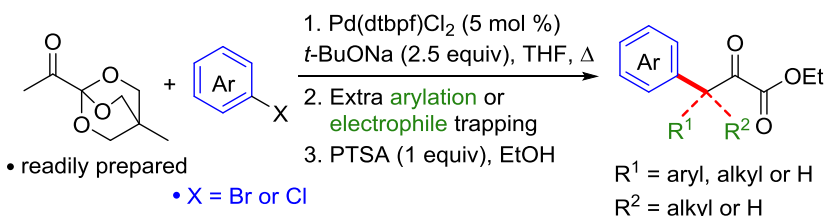

Pyruvic acids and esters are attractive building blocks in organic synthesis due to their densely situated reactive centers which can display both nucleophilic and electrophilic character. ${ }^{1}$ A variety of reactions have been described in the literature that utilize pyruvate substrates, such as a nitro-Mannich reaction, ${ }^{2}$ Michael addition, ${ }^{3}$ amination, ${ }^{4}$ aldol processes, ${ }^{5}$ fluorination $^{6}$ and $[3+2]$ cycloaddition. ${ }^{7}$ Such reactions are inherently useful and have been applied in the synthesis of cyclohexanes, ${ }^{8}$ dihydrofurans, ${ }^{9}$ dihydro-pyridazine-4carboxylic acids ${ }^{10}$ and 3 -deoxy-2-ulosonic acids. ${ }^{11}$ Despite this impressive range of applications, pyruvate chemistry still suffers from the major drawback that strongly basic media are not well tolerated, often causing decomposition of the pyruvate starting material (e.g. treatment of ethyl pyruvate with $t$-BuONa). ${ }^{7 \mathrm{a}}$

Inspired by this problem, we designed an orthoester-masked pyruvate equivalent (oxabicyclo[2.2.2]octyl orthoester, $\mathrm{OBO})^{12}$ robust enough to tolerate basic conditions that could potentially allow an expansion of the scope of pyruvate chemistry via Pd-catalyzed $\alpha$-arylation. ${ }^{13}$ Moreover, the $\alpha$-arylated pyruvates that could be prepared via this transformation would have the potential to serve as important and versatile synthetic intermediates. $^{14}$

Until very recently, the main methodologies available to install aryl groups at the $\alpha$-keto position of pyruvates relied on the condensation of aromatic aldehydes with $\mathrm{N}, \mathrm{N}$ dimethylglycine methyl ester followed by acidic hydrolysis, ${ }^{15}$ $\mathrm{Cu}$ (II)-catalyzed aerobic deacylation of acetoacetate esters ${ }^{16}$ or the oxidation of $\beta$-ketonitriles with PIDA. ${ }^{17}$ Although very useful, none of this methodologies delivers $\alpha, \alpha$-diarylated pyruvates or $\alpha$-quaternary centers and each method has its own limitations.

Some impressive work by Johnson and co-workers has recently accomplished the enolate $\alpha$-arylation of $\alpha$-alkyl-pyruvates using a hindered tert-butyl ester moiety and $\mathrm{K}_{2} \mathrm{CO}_{3}$ as a mild base, delivering $\alpha$-aryl- $\alpha$-alkyl-pyruvates in good yields (Scheme 1a). ${ }^{18}$ Concomitantly, we have explored an alternative approach based on the use of an OBO-masked pyruvate equivalent, which has facilitated the preparation of not only $\alpha$ aryl- $\alpha$-alkyl pyruvates, but also a combination of different mono and multiply $\alpha$-functionalized pyruvates (Scheme 1b). Notably, the variety of functionalities that can be installed at the $\alpha$-center considerably expands the range of pyruvates that can be synthesized, and should facilitate their use in future applications.

Scheme 1. Synthesis of arylated pyruvates.
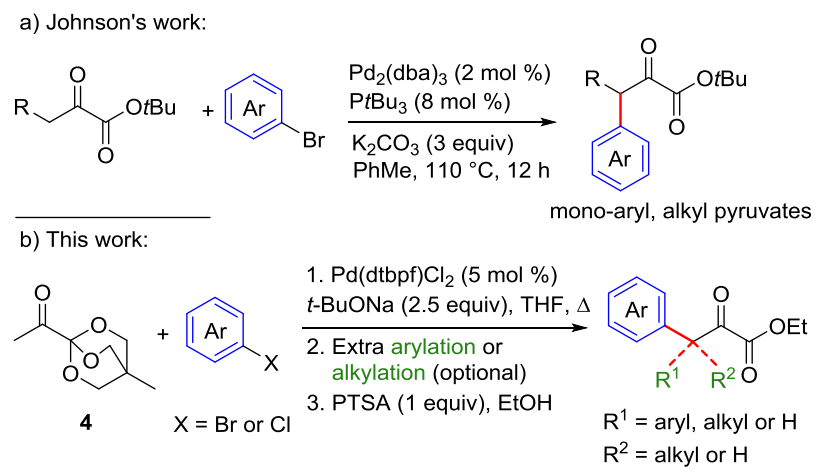

We began by preparing the OBO protected pyruvate ketone 4 via a convenient three step procedure, starting from pyruvic acid $\mathbf{1}$ and proceeding via intermediate ester $\mathbf{3}$ (Scheme 2). The overall yield for the synthesis was $49 \%$ and the sequence could be carried out on a multi-gram scale, requiring only filtration through a plug of silica and crystallisation to purify compound $\mathbf{4}$. 
Scheme 2. Synthesis of OBO protected pyruvate 4.

$$
\underset{1}{\stackrel{(\mathrm{COCl})_{2}(1.1 \text { equiv })}{\mathrm{DMF}^{2}(2 \mathrm{~mol} \%)}} \underset{\mathrm{CH}_{2} \mathrm{Cl}_{2}, \mathrm{rt}, 4 \mathrm{~h}}{\longrightarrow}
$$

We then examined the $\alpha$-arylation of compound 4 using aryl bromide $\mathbf{5}$, base and palladium catalysis, aiming to find general conditions for the introduction of an aryl group adjacent to the ketone, Table 1.

\begin{tabular}{|c|c|c|c|c|}
\hline 4 & $5(1.1$ & $\begin{array}{l}{[\mathrm{Pd}] \text { cata }} \\
\text { base, sol } \\
50{ }^{\circ} \mathrm{C}, 2 \\
\text { juiv) }\end{array}$ & $\begin{array}{l}\underset{\text { vent }}{\longrightarrow \text { hyst }} \\
4\end{array}$ & $\mathrm{O}$ \\
\hline entry & catalyst (5 mol\%) & solvent & base ( 2.5 equiv) & yield $\mathbf{6 a}(\%)^{a}$ \\
\hline 1 & $\mathrm{Pd}(\text { Amphos })_{2}$ & THF & $t$-BuONa & 0 \\
\hline 2 & $\mathrm{Pd}($ QPhos)(crotyl)Cl & THF & $t$-BuONa & 40 \\
\hline 3 & $\mathrm{Pd}\left(t-\mathrm{Bu}_{3} \mathrm{P}\right)($ allyl $) \mathrm{Cl}$ & THF & $t$-BuONa & 64 \\
\hline 4 & $\mathrm{Pd}\left(\mathrm{Ph}_{3} \mathrm{P}\right)\left(\mathrm{PhCH}_{2}\right) \mathrm{Cl}$ & THF & $t$-BuONa & 0 \\
\hline 5 & $\mathrm{Pd}(\operatorname{cod}) \mathrm{Cl}_{2}$ & THF & $t$-BuONa & 52 \\
\hline 6 & $\mathrm{Pd}(\mathrm{dtbpf}) \mathrm{Cl}_{2}$ & THF & $t$-BuONa & 85 \\
\hline $7^{b}$ & $\mathrm{Pd}(\mathrm{dtbpf}) \mathrm{Cl}_{2}$ & THF & $t$-BuONa & $0^{c}$ \\
\hline 8 & $\mathrm{Pd}(\mathrm{dtbpf}) \mathrm{Cl}_{2}$ & toluene & $t$-BuONa & 39 \\
\hline 9 & $\mathrm{Pd}(\mathrm{dtbpf}) \mathrm{Cl}_{2}$ & DCE & $t$-BuONa & 51 \\
\hline 10 & $\mathrm{Pd}(\mathrm{dtbpf}) \mathrm{Cl}_{2}$ & dioxane & $t$-BuONa & 44 \\
\hline 11 & $\mathrm{Pd}(\mathrm{dtbpf}) \mathrm{Cl}_{2}$ & THF & LiHMDS & 0 \\
\hline 12 & $\mathrm{Pd}(\mathrm{dtbpf}) \mathrm{Cl}_{2}$ & THF & $\mathrm{Cs}_{2} \mathrm{CO}_{3}$ & 14 \\
\hline $\begin{array}{l}{ }^{a} \text { Isola } \\
\text { Amp } \\
\text { QPh } \\
\text { dtbp }\end{array}$ & $\begin{array}{l}\text { ed yields; }{ }^{b} \text { temperature }=7 \\
\text { los }=\text { di-tert-butyl }(4 \text {-dimethy } \\
\text { s }=1,2,3,4,5 \text {-pentaphenyl- } 1 \\
=1,1^{\prime} \text {-bis(di-tert-butylphosp }\end{array}$ & $\begin{array}{l}{ }^{C}{ }^{c}{ }^{c} \text { diarylate } \\
\text { ninophenyl)p } \\
\text { di-tert-butylp } \\
\text { oo)ferrocene }\end{array}$ & $\begin{array}{l}\text { ed material was isolate } \\
\text { hosphine } \\
\text { hosphino)ferrocene }\end{array}$ & \\
\hline
\end{tabular}

Table 1. Optimization of the $\alpha$-arylation of compound 4 .

Our summary of the screening results, shown in Table 1, reveals that product $6 \mathbf{a}$ could be formed using a variety of different catalysts, bases and solvent. However, pre-formed $\mathrm{Pd}(\mathrm{dtbpf}) \mathrm{Cl}_{2}$ performed best as the catalyst, with $t-\mathrm{BuONa}$ as the preferred base in THF (entry 6). Interestingly, an increase of the reaction temperature to $75{ }^{\circ} \mathrm{C}$ (entry 7) did not allow the isolation of any monoarylated compound $\mathbf{6 a}$, but instead led to complete formation of the diarylated material (vide infra).

The optimal conditions were then applied to the arylation of 4 using a wide variety of aryl bromides (Scheme 3a). It can be seen that electron-rich, electron-deficient and heteroaromatic arenes were all compatible with the reaction. Amides, styrenes and TBS protected phenols were also tolerated, proving the broad applicability of this method. Pleasingly, substitution was allowed at every position on the phenyl ring. It is also noteworthy that despite the preference for aryl bromides (see example 6f), aryl chlorides are also viable starting materials for this chemistry (Scheme 3b), with compounds 6r-t being readi- ly preparable in good yield. In order to demonstrate synthetic utility, a single example (6c) was conducted on a gram scale using a lower catalyst loading and relying on a single crystallization as the purification method. Given the crystalline nature of many of these arylation products, this is an important feature for the future scale-up of this methodology.

Scheme 3. Scope of the mono-arylation reaction.
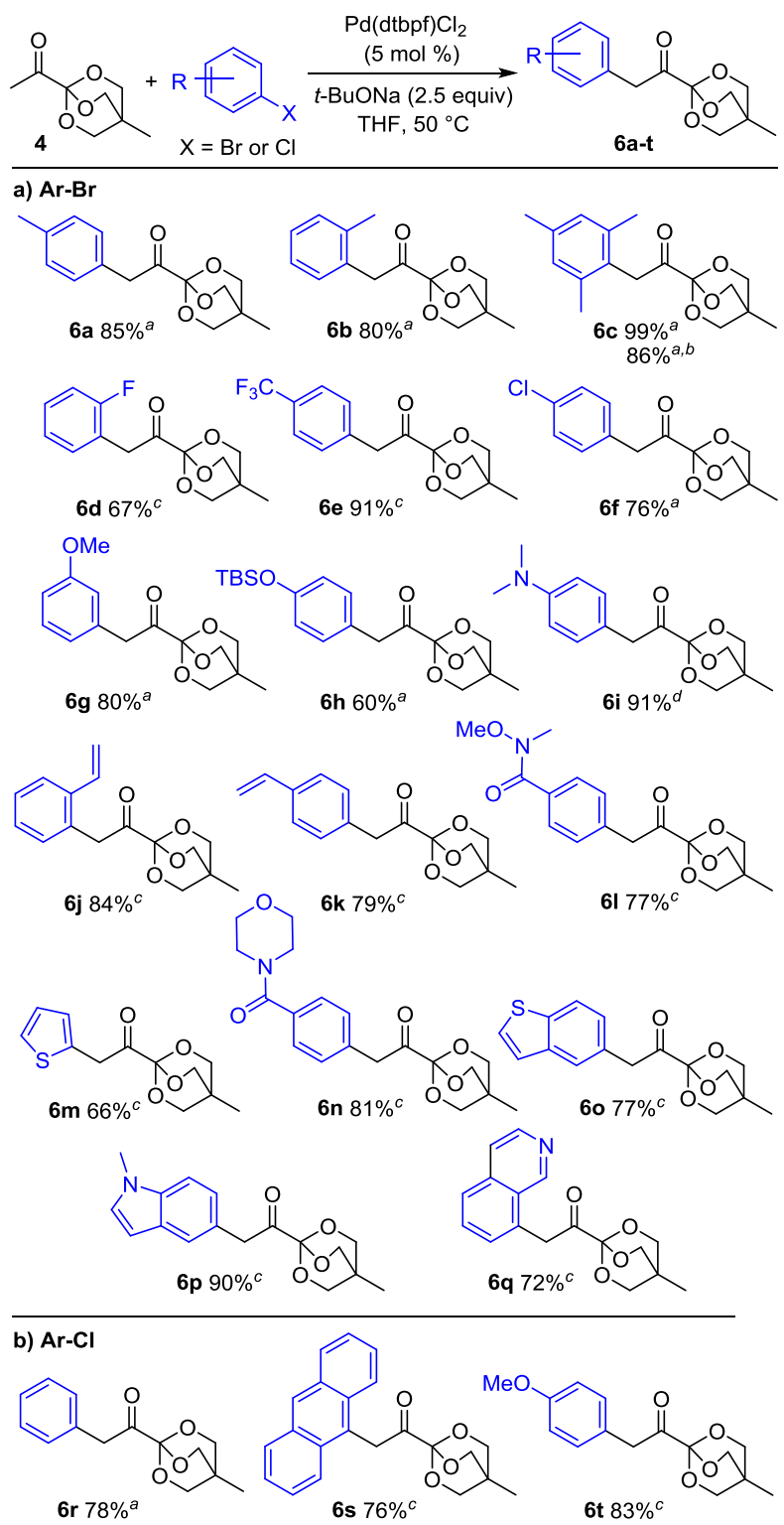

Conditions: ${ }^{a} 4$ (1.0 equiv), aryl halide ( 1.1 equiv), $50{ }^{\circ} \mathrm{C}, 24 \mathrm{~h} ;{ }^{b}$ gram-scale reaction with $2 \mathrm{~mol} \%$ catalyst; ${ }^{c} \mathbf{4}$ (1.5 equiv), aryl halide (1.0 equiv), $70^{\circ} \mathrm{C}$, $24 \mathrm{~h} ;{ }^{d} \mathbf{4}$ (1.5 equiv), aryl halide (1.0 equiv), $50{ }^{\circ} \mathrm{C}, 24 \mathrm{~h}$

Building on the observation of double arylation products when the reaction temperature was raised (see Table 1, entry 7), we conducted a set of arylations that introduced two equivalent aryl groups simply by adding 3 equivalents of the aryl bromide and heating the reaction to $80{ }^{\circ} \mathrm{C}$ (Scheme 4). In addition, heterodiarylated products were formed in good yields when we ran the arylation reaction with one equivalent of one aryl halide and then added an excess of another, different, aryl halide after $8 \mathrm{~h} .{ }^{19}$ Interestingly, the products $\mathbf{7 c}$ and $\mathbf{7 d}$ formed 
in this manner could be made in good yield with the $p$ dimethylamino bromobenzene used as either the first (7d) or second (7c) aryl coupling partner.

Scheme 4. Diarylation for homo- and heterodiaryl products.
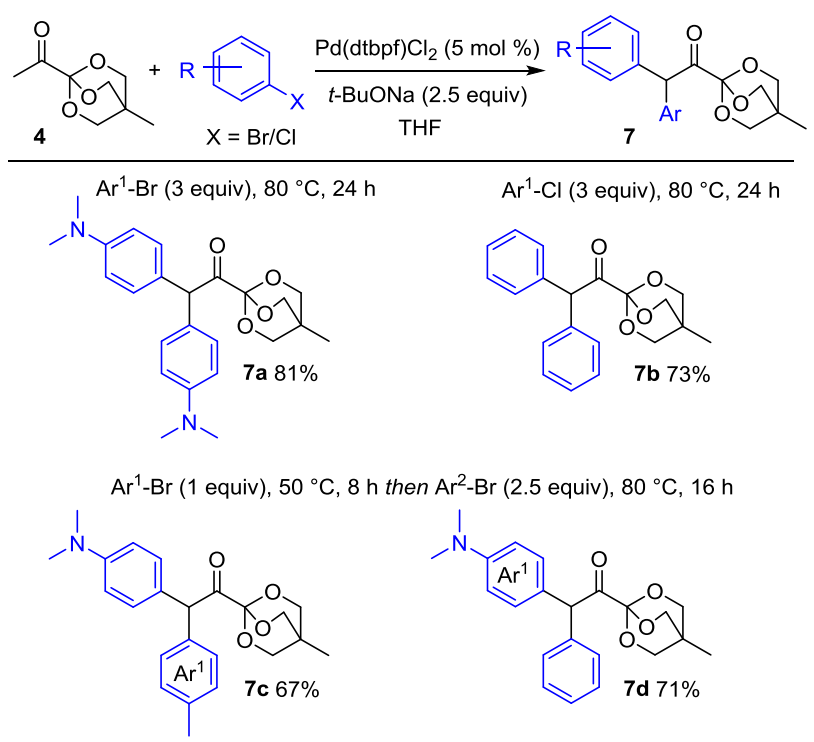

The enolate arylation reaction requires at least two equivalents of base to achieve clean mono-arylation, as the product is more acidic than the starting material. ${ }^{20}$ Hence, the initially formed aryl ketone is deprotonated in situ by the excess base.

Scheme 5. One-pot arylation and alkylation sequences.
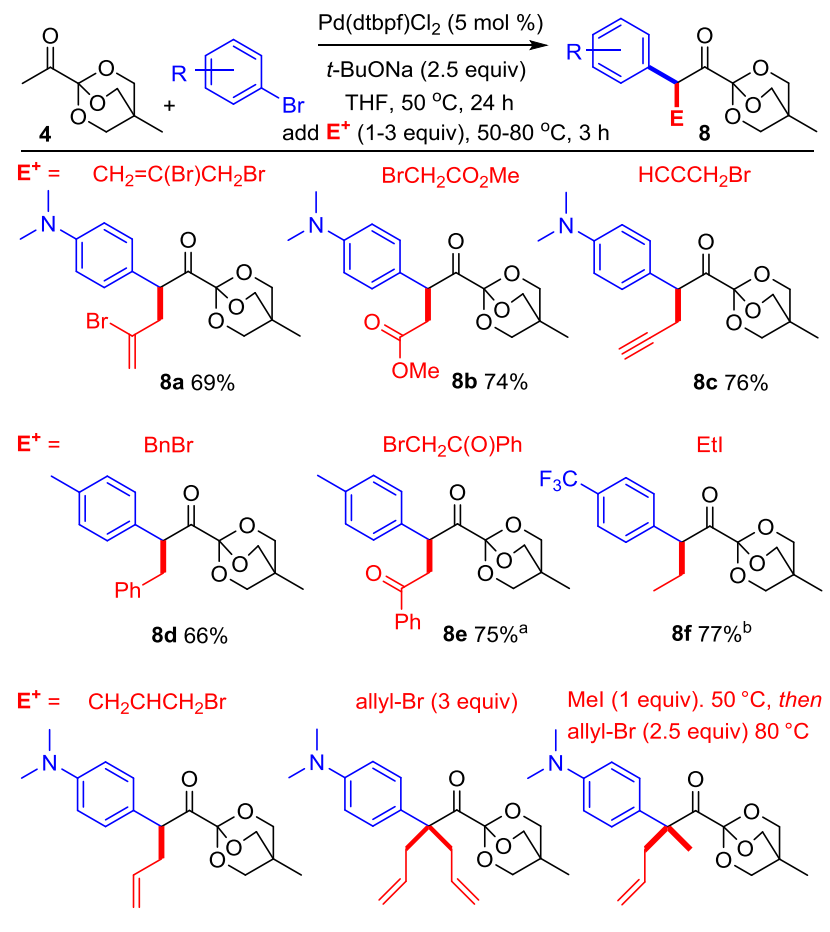

$8 \mathrm{~g} 82 \%$

8 h $85 \%^{a}$

$8 \mathbf{i} 48 \%$

a Reaction heated to $80^{\circ} \mathrm{C}$ for $8 \mathrm{~h}$ after addition of electrophile.

${ }^{\mathrm{b}}$ Reaction temperature was $70^{\circ} \mathrm{C}$ throughout.
Consequently, we found it possible to quench the reaction directly with an electrophile and so generate doubly functionalized products in one pot. The results shown in Scheme 5 (8ag) illustrate that several different aryl halides can be combined with different electrophile traps and thus form a variety of products as shown. In fact, the addition of excess electrophile (allyl bromide) and extra base after the arylation reaction allowed a double allylation reaction to proceed (see $\mathbf{8 h}$, Scheme 5). Finally, by adding methyl iodide (1 equiv) followed by allyl bromide and extra base, we were able to perform a one-pot arylation and then a sequential double alkylation reaction to form compound $\mathbf{8 i}$ in $48 \%$ yield.

Clearly, if this reaction methodology is to prove useful in organic synthesis it is imperative that we are able to deprotect the OBO moiety. Therefore, a series of representative compounds were treated with PTSA (1 equiv) in ethanol under heating in a sealed vial (Scheme 6). Pleasingly, in each case the corresponding ethyl ester 9a-f was formed in good yields. This method was applicable to mono- and di-arylated substrates as well as compounds containing aryl and alkyl substituents.

\section{Scheme 6. Removal of the OBO protecting group.}

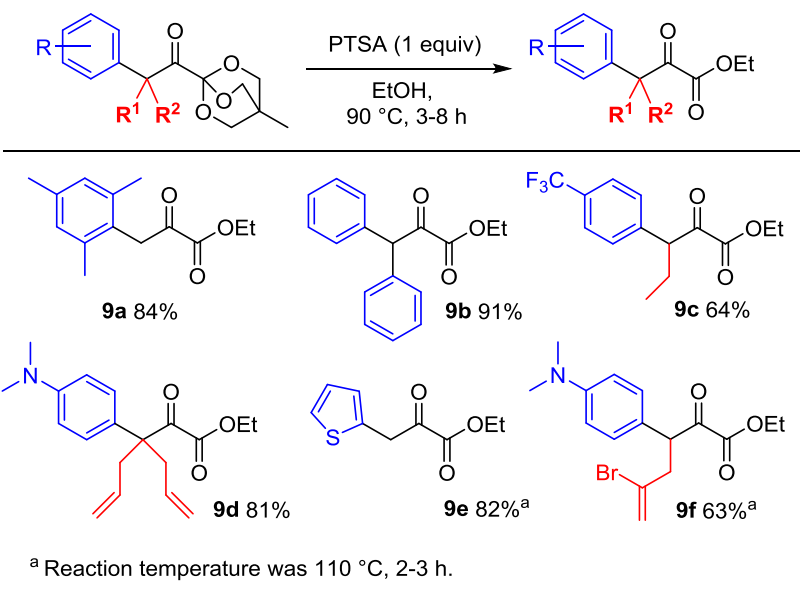

Finally, in order to demonstrate the utility of this chemistry, we addressed the one-pot arylation/deprotection sequences shown in Scheme 7. The first three examples illustrate that the OBO ketone $\mathbf{4}$ could be conveniently transformed into various arylated and further functionalised pyruvate esters in one-pot (punctuated with a solvent change) and in good yield. The formation of pyruvic acids by OBO deprotection was also investigated but we found that the polar products were extremely difficult to purify. Therefore, we have restricted ourselves to the one example shown (10) in which the product was recovered in high purity from aqueous extraction. However, this single example shows that it is possible to produce the arylated pyruvic acid directly from compound 4 .

Scheme 7. One-pot arylation and deprotection sequence. 


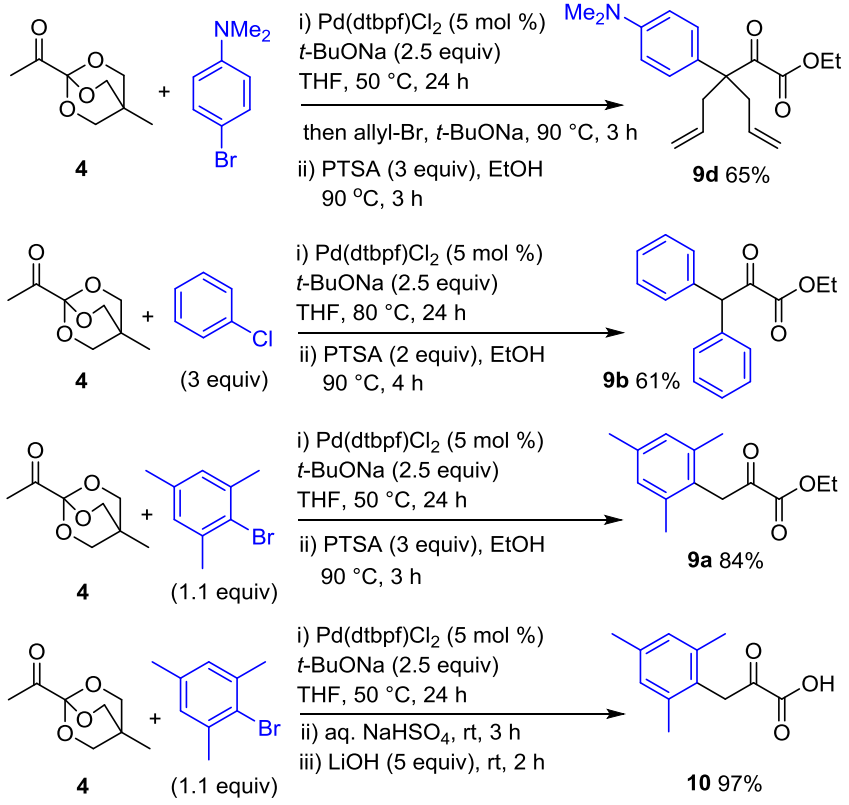

A new method for the enolate arylation of protected pyruvate esters has been presented. The methodology allows mono- and diarylation reactions to take place on an easily accessible OBO protected starting material. Moreover, the mono-arylated intermediates could be readily alkylated in situ to allow the formation of a wide range of differently substituted pyruvate equivalents. Finally, the OBO protecting group could be removed conveniently using acidic conditions.

\section{ASSOCIATED CONTENT}

Supporting Information The Supporting Information is available free of charge on the ACS Publications website.

Full experimental details, copies of spectral data (PDF).

\section{AUTHOR INFORMATION}

\section{Corresponding Author}

* E-mail: timothy.donohoe@chem.ox.ac.uk.

Notes The authors declare no competing financial interest.

\section{ACKNOWLEDGMENT}

We thank CAPES, Coordenação de Aperfeiçoamento de Pessoal de Nível Superior, Brazil and AstraZeneca for supporting this project.

\section{REFERENCES}

(1) Raimondi, W.; Bonne, D.; Rodriguez, J. Chem. Commun. 2012, 48, 6763 .

(2) Nishiwaki, N.; Knudsen, K. R.; Gothelf, K. V.; Jørgensen, K. A. Angew. Chem. Int. Ed. 2001, 40, 2992.

(3) (a) Nakamura, A.; Lectard, S.; Hashizume, D.; Hamashima, Y.; Sodeoka, M. J. Am. Chem. Soc. 2010, 132, 4036. (b) Baslé, O.; Raimondi, W.; Duque, M. M. S.; Bonne, D.; Constantieux, T.; Rodriguez, J. Org. Lett. 2010, 12, 5246.
(4) (a) Juhl, K.; Jørgensen, A. J. Am. Chem. Soc. 2002, 124, 2420. (b) Terada, M.; Amagai, K.; Ando, K.; Kwon, E.; Ube, H. Chem. Eur. J. 2011, 17, 9037.

(5) (a) Juhl, K.; Gathergood, N.; Jørgensen, K. A. Chem. Commun. 2000, 2211. (b) Torii, H.; Nakadai, M.; Ishihara, K.; Saito, S.; Yamamoto, H. Angew. Chem. Int. Ed. 2004, 43, 1983. (c) Bhasker, V.; Hagihara, K.; Rawal, V. H. Chem. Commun. 2010, 46, 904.

(6) Suzuki, S.; Kitamura, Y.; Lectard, S.; Hamashima, Y.; Sodeoka, M. Angew. Chem. Int. Ed. 2012, 51, 4581.

(7) (a) Sohtome, Y.; Nakamura, G.; Muranaka, A.; Hashizume, D.; Lectard, S.; Tsuchimoto, T.; Uchiyama, M.; Sodeoka, M. Nat. Commun. 2017, 8, 14875. (b) Bartlett, S. L.; Sohtome, Y.; Hashizume, D.; White, P. S.; Sawamura, M.; Johnson, J. S.; Sodeoka, M. J. Am. Chem. Soc. 2017, 139, 8661.

(8) Shi, D.; Xie, Y.; Zhou, H.; Xia, C.; Huang, H. Angew. Chem. Int. Ed. 2012, 51, 1248.

(9) Becerra, D.; Raimondi, W.; Dauzonne, D.; Constantieux, T.; Bonne, D.; Rodriguez, R. Synthesis 2017, 49, 195.

(10) Murphy, D. E.; Dragovich, P. S.; Ayida, B. K.; Bertolini, T. M.; Li, L. -S.; Ruebsam, F.; Stankovic, N. S.; Sun, Z.; Zhao, J.; Zhou, Y. Tetrahedron Lett. 2008, 49, 811.

(11) Molenda, M. A.; Bás, S.; Mlynarski, J. Eur. J. Org. Chem. 2016, 25, 4394.

(12) (a) Corey, E. J.; Raju, N. Tetrahedron Lett. 1983, 24, 55715574. During the course of our studies, a report was published exploring the properties of $\mathbf{4}$ in diastereoselective aldol reactions: (b) Norimura, Y.; Yamamoto, D.; Makino, K. Org. Biomol. Chem. 2017, 15, 640.

(13) (a) Hamann, B. C.; Hartwig, J. F. J. Am. Chem. Soc. 1997, 119, 12382. (b) Palucki, M.; Buchwald, S. L. J. Am. Chem. Soc. 1997, 119, 11108. (c) Satoh, T.; Kawamura, Y.; Miura, M.; Nomura, M. Angew. Chem., Int. Ed. 1997, 36, 1740. For reviews: (d) Bellina, F.; Rossi, R. Chem. Rev. 2010, 110, 1082. (e) Johansson, C. C. C.; Colacot, T. J. Angew. Chem., Int. Ed. 2010, 49, 676. (14) (a) Potukuchi, H. K.; Spork, A. P.; Donohoe, T. J. Org. Biomol. Chem. 2015, 13, 4367. (b) Donohoe, T. J.; Pilgrim, B. S.; Jones, G. R.; Bassuto, J. A. Proc. Natl. Acad. Sci. U.S.A. 2012, 109, 11605. (c) Pilgrim, B.; Gatland, A. E.; McTernan, C.; Procopiou, P.; Donohoe, T. J. Org. Lett. 2013, 15, 6190. (d) Gatland, A. E.; Pilgrim, B. S.; Procopiou, P. A.; Donohoe, T. J. Angew. Chem. Int. Ed. 2014, 53, 14555. (e) Pilgrim, B. S.; Gatland, A. E.; Esteves, C. H. A.; McTernan, C. T.; Jones, G. R.; Tatton, M. R.; Procopiou, P. A.; Donohoe, T. J. Org. Biomol. Chem. 2016, 14, 1065. (f) Hardegger, L. A.; Habegger, J.; Donohoe, T. J. Org. Lett. 2015, 17, 3222.

(15) (a) Horner, L.; Renth, E. O. Liebigs Ann. Chem. 1967, 703, 37. (b) Sivanathan, S.; Körber, F.; Tent, J. A.; Werner, S.; Scherkenbeck, J. J. Org. Chem. 2015, 80, 2554.

(16) Steward, K. M.; Johnson, J. S. Org. Lett. 2011, 13, 2426.

(17) Xie, Y.; Liu, J. Huang, Y.; Yao, L. Tetrahedron Lett. 2015, $56,3793$.

(18) Zavesky, B. P.; Bartlett, S. L.; Johnson, J. S. Org. Lett. 2017, $19,2126$.

(19) (a) Churruca, F.; SanMartin, R.; Carril, M.; Tellitu, I.; Domínguez, E. Tetrahedon 2004, 60, 2393-2408; (b) Cao, C.; Wang, L.; Cai, Z.; Zhang, L.; Guo, J.; Pang, G.; Shi, Y. Eur. J. Org. Chem. 2011, 1570-1574.

(20) (a) Kawatsura, M.; Hartwig, J. F. J. Am. Chem. Soc. 1999, 121, 1473. (b) Culkin, D. A.; Hartwig, J. F. Acc. Chem. Res. 2003, 36, 234. (c) Grasa, G. A.; Colacot, T. J. Org. Lett. 2007, 9, 5489. 